\title{
Introduction to nanoMIPS Prepared by Solid-Phase approach as an Alternative for Antibodies in the pseudo-ELISA Diagnostic Assay
}

\author{
Katarzyna Smolinska-Kempisty ${ }^{1 *}$ and Joanna Czulak ${ }^{2}$ \\ ${ }^{1}$ Department of Polymer and Carbon Materials, Wroclaw University of Science and Technology, Poland \\ ${ }^{2}$ MIP Diagnostics Ltd., Colworth Park, Sharnbrook, UK
}

*Corresponding author: Katarzyna Smolinska-Kempisty, Department of Polymer and Carbon Materials, Wroclaw University of Science and Technology, Poland.

To Cite This Article: Katarzyna Smolinska-Kempisty. Introduction to nanoMIPS Prepared by Solid-Phase approach as an Alternative for Antibodies in the pseudo-ELISA Diagnostic Assay. Am J Biomed Sci \& Res. 2019 - 5(1). AJBSR.MS.ID.000862. DOI: 10.34297/AJBSR.2019.05.000862

Received: 眥August 27, 2019; Published: 眥August 29, 2019

\begin{abstract}
The presented article describes the possibilities of replacing antibodies with artificial molecules in the pseudo-ELISA diagnostic assay. The enzyme-linked immunosorbent assay ELISA is based on specific antibodies, linked to an enzyme, to detect the determined molecule. However, the production of antibodies is complicated and therefore its price is high. Also, the stability of the antibodies is inadequate for their price. For this reason, research into artificial molecules that could replace natural immunoglobulins is becoming extremely important. The article presents studies comparing the use of antibodies and molecularly imprinted nano molecules, nanoMIPs, as artificial antibodies in the ELISA assay.

Keywords: nanoMIPS; pseudo-ELISA; Solid phases imprinted method
\end{abstract}

\section{Introduction}

The principle of antibody activity is based on the recognition and binding of antibodies to an antigen, or more precisely an epitope. This means that each antibody molecule has a specific binding site. Multi specific antibodies are able to recognize and bind to more than one antigen. In contrast, monoclonal antibodies bind to only one specific antigen and thus are characterized by their high affinity and selectivity [1,2]. Considering the complexity and sophistication of these molecules, creating their artificial counterparts is not easy. The difficulty of this task is confirmed by the fact that researchers have been working on this type of material for over 25 years. The first demonstration that the recognition material in diagnostic assays can be replaced by artificial antibodies based on molecularly imprinted polymers (MIPs) was published in 1993 [3]. MIPs are synthetic materials, polymerized in the presence of a specific target molecule called the 'template'. The template molecule can be considered as an antigen or in some cases as a fragment of the antigen molecule. They are based mainly on acrylic or methacrylic monomers which functionality enables to form a monomer-template complex in a very similar manner as the interactions between amino acids (from antibody) and antigen are formed [4]. Superior of MIPs compared with natural antibodies is also reflected in the types of the analytes that MIPs can be produced for such as toxins and some pesticides which prove to be difficult to produce antibodies for. In effect, the plastic antibodies/imprinted polymers in various formats (nanoparticle or film/microparticles) have successfully been produced against a wide range of targets such as: ions (phosphate[5], carbonate[6], copper ions [7], small molecules (caffeine[8], cocaine[9], melamine[10], ascorbic acid[11], sugars[12], fentanyl[13], doxorubicin[14,15], phosphorganic pesticides[16], explosives[17], etc), peptides (vancomycin[18-20], peptides/protein epitopes [21,22]), proteins (trypsin[21,23,24], acetylcholinesterase [25]), E. coli [26].

The further development of solid-phase imprinted method made it possible to obtain particles with surface imprinting in nano sizes with the similarity to monoclonal antibodies [4]. This method is based on interactions between the monomer and the functional groups present in the template, which is previously immobilized on the solid phase. After the polymerization process, the low-affinity particles and non-reacted monomers are removed by the low-temperature washes. Subsequently, the temperature is raised and the high affinity nano MIPs are collected while the template molecule is still attached to the solid phase. The template-derived sites created within a polymeric matrix allow MIPs to selectively recognize and bind to the target molecule (antigen) [27-31]. Produced nanoMIPs 
are more resistant to chemical and biological damage and inactivation than antibodies [26]. For this reason, the imprinted nanoparticles have high potential to be generic alternatives to antibodies in sensors, diagnostics, separations and in enzyme-linked immunosorbent diagnostic assays [19,31,32]. One of the first results, showing the advantage of the technology, were published in 2013 and presents the use of nano MIPs in the new, highly specific, sensitive, and clinically relevant enzyme-linked assay for vancomycin detection [19].

The developed assay was based on nanoMIPs-coated microplates and allowed the accurate determination of vancomycin over the concentration range of $0.001-70 \mathrm{nM}$, with a limit of detection of $0.0025 \mathrm{nM}$ (Figure 1). It also allows determining vancomycin in plasma at clinically relevant concentrations with a mean accuracy of $98 \%$ and very low cross-reactivity with three other antibiotics (amoxicillin, gentamicin, and bleomycin) comparable to high-quality monoclonal antibodies [19]. Another interesting approach, based on nanoMIPs with the catalytic core, provides a new route towards replacement of unstable biomolecules in immunoassays and fully abiotic assays where the nanoparticles possess both recognition and signaling properties [33]. The nanoMIPs were also successfully synthesized for another antibiotic - gentamicin and used in pseudo-ELISA assay. This antibiotic was determined in milk at clinically relevant concentrations with a mean accuracy of $94 \%$. The cross-reactivity of such nanoparticles was investigated with streptomycin and ampicillin as control antibiotics, demonstrating excellent specificity [34].

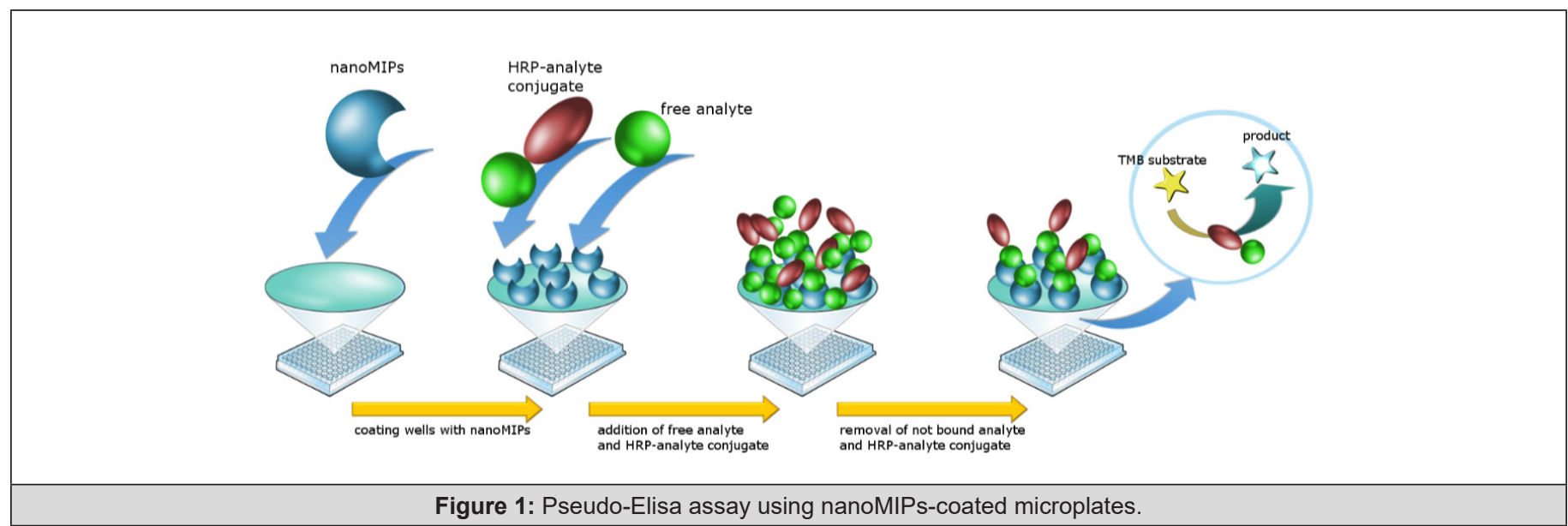

The nano MIPs can be created with relatively short development times for various types of molecules and still demonstrate comparable or better performance to commercially produced antibodies in enzyme-linked competitive assays (Table 1) [35]. It has been also shown that the polymerization type has influence on the nano MIPs performance in the pseudo-Elisa assays depending on the size of imprinted molecule [10]. The studies concluded that the best performances were obtained for particles synthesized in aqueous media for the larger analytes such as horseradish peroxidase (HRP. $44 \mathrm{kDa}$ ), cytochrome C (Cyt C. $12 \mathrm{kDa}$ ) and biotin (244.31 g mol-1) but completely failed for the smallest template melamine (126.12 g mol-1). The high-performance Elisa for melamine was therefore achieved using nanoMIPs prepared by UV polymerization in an organic media with a shell created by poly (glycol ethanol).

\begin{tabular}{|c|c|c|c|}
\hline Table 1: Limit of detection, LoD for nanoMIPs and antibodies-based assay. & \multicolumn{3}{|c|}{ Ref. } \\
\hline Template & LoD, nano MIP based assay, nM & LoD, Antibodies based assay, nM & {$[35]$} \\
\hline Biotin & $1.20 \times 10-3$ & $2.54 \times 10-3$ & {$[3.5$} \\
\hline L-Thyroxine & $8.07 \times 10-3$ & $3.38 \times 10-4$ & {$[35]$} \\
\hline Glucosamine & $4.01 \times 10-4$ & $2.5 \times 10-2$ & {$[35]$} \\
\hline Fumonisine B2 & $6.12 \times 10-3$ & $4.18 \times 10-2$ & {$[36]$} \\
\hline Fumonisine B1 & $1.90 \times 10-3$ & $1.54 \times 10-4$ & {$[37]$} \\
\hline Hemoglobine & $8.70 \times 10-3$ & $2.38 \times 10-4$ & {$[37]$} \\
\hline Glycated hemoglobin & $2.46 \times 10-3$ & - & {$[19]$} \\
\hline Vancomycin & $2.50 \times 10-3$ & - & {$[34]$} \\
\hline Gentamycin & $1 \times 10-4$ & - & {$[10]$} \\
\hline Horseradish peroxidase & 0.5 & - & {$[10]$} \\
\hline Cytochrome C & 45 & - & {$[10]$} \\
\hline Melamine & 25 & - & {$[38]$} \\
\hline LC-mycocistin & $2.64 \times 10-4$ & 3.3 & \\
\hline Cocaine & $4.24 \times 10-3$ & {$[38]$} \\
\hline
\end{tabular}


In conclusion, the nanoMIPs prepared by solid-phase imprinted methods have high potential to replace antibodies in pseudo-ELISA assays with high specificity and no cross-reactivity. Moreover, the nanoMIP-coated microplates can withstand exposure to high temperature for prolonged periods without affecting the sensitivity of the assay. Conducted research suggested also that microplates coated with nanoMIPs do not require refrigeration during transportation and were also stable during the storage at room temperature for at least 1 month, which brings additional social and economic benefits $[19,33]$.

\section{References}

1. Singh S, Tank NK, Dwiwedi P, Charan J, Kaur R, et al. (2018) Monoclonal Antibodies: A Review. Curr Clin Pharmacol 13(2): 85-99.

2. Tsetsos N, Goudakos JK, Daskalakis D, Konstantinidis I, Markou K (2018) Monoclonal antibodies for the treatment of chronic rhinosinusitis with nasal polyposis: a systematic review. Rhinology 56(1): 11-21.

3. Vlatakis G, Andersson LI, Müller R, Mosbach K (1993) Drug assay using antibody mimics made by molecular imprinting. Nature 361(6413): 645-647.

4. Canfarotta F, Poma A, Guerreiro A, Piletsky S (2016) Solid-phase synthesis of molecularly imprinted nanoparticles. Nat Protoc 11(3): 443-55.

5. Warwick C, Guerreiro A, Gomez Caballero A, Wood E, Kitson J, et al. (2014) Conductance based sensing and analysis of soluble phosphates in wastewater. Biosens Bioelectron 52: 173-179.

6. Boonpangrak S, Prachayasittikul V, Bülow L, Ye L (2006) Molecularly imprinted polymer microspheres prepared by precipitation polymerization using a sacrificial covalent bond. J Appl Polym Sci 99(4): 1390-1398.

7. Di Masi S, Garcia Cruz A, Canfarotta F, Cowen T, Marote P, et al. (2019) Synthesis and Application of Ion-Imprinted Nanoparticles in Electrochemical Sensors for Copper (II) Determination. Chem Nano Mat 5(6) 754-760.

8. Tian DT, Zhou YC, Xiong L, Lu FT (2017) Synthesis and Properties of Caffeine Molecularly Imprinted Polymers Based on Konjac Glucomannan. Adv Polym Technol 36(1): 68-76.

9. Smolinska Kempisty K, Ahmad OS, Guerreiro A, Karim K, Piletska E, et al. (2017) New potentiometric sensor based on molecularly imprinted nanoparticles for cocaine detection. Biosens Bioelectron 96: 49-54.

10. Caceres C, Canfarotta F, Chianella I, Pereira E, Moczko E, et al. (2016) Does size matter? Study of performance of pseudo-ELISAs based on molecularly imprinted polymer nanoparticles prepared for analytes of different sizes. Analyst 141(4): 1405-1412.

11. Roy AK, SNV, Dhand C, Malhotra BD (2011) Molecularly imprinted polyaniline film for ascorbic acid detection. J Mol Recognit 24(4): 700-706.

12. Piletsky SS, Rabinowicz S, Yang Z, Zagar C, Piletska E V, et al. (2017) Development of molecularly imprinted polymers specific for blood antigens for application in antibody-free blood typing. Chem Commun 53(11): 1793-1796.

13. Bagheri H, Piri-Moghadam H, Bayat P, Balalaie S (2013) Application of sol-gel based molecularly imprinted xerogel for on-line capillary microextraction of fentanyl from urine and plasma samples. Anal Methods 5(24): 7096-7101.

14. Ahmadi M, Madrakian T, Afkhami A (2015) Solid phase extraction of doxorubicin using molecularly imprinted polymer coated magnetite nanospheres prior to its spectrofluorometric determination. New J Chem 39(1): 163-171.

15. Canfarotta F, Lezina L, Guerreiro A, Czulak J, Petukhov A, et al. (2018) Specific Drug Delivery to Cancer Cells with Double-Imprinted Nanopar- ticles against Epidermal Growth Factor Receptor. Nano Lett 18(8): 46414646.

16. Esen C, Czulak J, Cowen T, Piletska E, A. Piletsky S (2018) Highly Efficient Abiotic Assay Formats for Methyl Parathion: Molecularly Imprinted Polymer Nanoparticle Assay as an Alternative to Enzyme-Linked Immunosorbent Assay. Anal Chem 91(1): 958-964.

17. Zarejousheghani M, Lorenz W, Vanninen P, Alizadeh T, Cämmerer M, et al. (2019) Molecularly Imprinted Polymer Materials as Selective Recognition Sorbents for Explosives: A Review. Polymers 11(5): 888.

18. Czulak J, Guerreiro A, Metran K, Canfarotta F, Goddard A, et al. (2016) Formation of target-specific binding sites in enzymes: solid-phase molecular imprinting of HRP. Nanoscale 8(21): 11060-11060.

19. Chianella I, Guerreiro A, Moczko E, Caygill JS, Piletska E V, et al. (2013) Direct replacement of antibodies with molecularly imprinted polymer (MIP) nanoparticles in ELISA-development of a novel assay for vancomycin. Anal Chem 85(17): 8462-8468.

20. Korposh S, Chianella I, Guerreiro A, Caygill S, Piletsky S, et al. (2014) Selective vancomycin detection using optical fibre long period grat ings functionalised with molecularly imprinted polymer nanoparticles 139(9): 2229-2236

21. Canfarotta F, Czulak J, Betlem K, Sachdeva A, Eersels K, et al. (2018) A novel thermal detection method based on molecularly imprinted nanoparticles as recognition elements. Nanoscale 10(4): 2081-2089.

22. Motib A, Guerreiro A, Al-Bayati F, Piletska E, Manzoor I, et al. (2017) Modulation of Quorum Sensing in a Gram-Positive Pathogen by Linear Molecularly Imprinted Polymers with Anti-infective Properties. Angew Chemie Int Ed 56(52): 16555-16558.

23. Ertürk G, Hedström M, Mattiasson B. (2016) A sensitive and real-time assay of trypsin by using molecular imprinting-based capacitive biosensor. Biosens Bioelectron 86: 557-565.

24. Canfarotta F, Czulak J, Guerreiro A, Cruz AG, Piletsky S, et al. (2018) A novel capacitive sensor based on molecularly imprinted nanoparticles as recognition elements. Biosens Bioelectron 120: 108-114.

25. Jetzschmann KJ, Jágerszki G, Dechtrirat D, Yarman A, Gajovic-Eichelmann N, et al. (2015) Vectorially Imprinted Hybrid Nanofilm for Acetylcholinesterase Recognition. Adv Funct Mater 25(32): 5178-5183.

26. Altintas Z, Gittens M, Guerreiro A, Thompson KA, Walker J, et al. (2015) Detection of Waterborne Viruses Using High Affinity Molecularly Imprinted Polymers. Anal Chem 87(13): 6801-6807.

27. Canfarotta F, Waters A, Sadler R, McGill P, Guerreiro A, et al. (2016) Biocompatibility and internalization of molecularly imprinted nanoparticles. Nano Res 9(11): 3463-3477.

28. Chen L, Muhammad T, Yakup B, Piletsky SA (2017) New immobilisation protocol for the template used in solid-phase synthesis of MIP nanoparticles. Appl Surf Sci 406: 115-21.

29. Jatin M, Guerreiro A, Moczko E, Piletska E, Karim K, et al. (2015) Analysis of cooperative interactions in molecularly imprinted polymer nanoparticles. Molecular Imprinting 3(1): 55-64.

30. Poma A, Guerreiro A, Caygill S, Moczko E, Piletsky S (2014) Automatic reactor for solid-phase synthesis of molecularly imprinted polymeric nanoparticles (MIP NPs) in water. RSC Adv 4(8): 4203-4206.

31. Poma A, Guerreiro A, Whitcombe MJ, Piletska EV, Turner APF, et al. (2013) Solid-Phase Synthesis of Molecularly Imprinted Polymer Nanoparticles with a Reusable Template-“Plastic Antibodies." Adv Funct Mater 23(22): 2821-2827.

32. Canfarotta F, Smolinska-Kempisty K, Piletsky SA (2017) Replacement of Antibodies in Pseudo-ELISAs: Molecularly Imprinted Nanoparticles for Vancomycin Detection. In: Methods in Molecular Biology 1575: 389-398.

33. Shutov RV, Guerreiro A, Moczko E, De Vargas-Sansalvador IP, Chianella I, 
et al. (2014) Introducing MINA - The Molecularly Imprinted Nanoparticle Assay 10(6):1086-1089.

34. Tang SP, Canfarotta F, Smolinska Kempisty K, Piletska E, Guerreiro A, et al. (2017) A pseudo-ELISA based on molecularly imprinted nanoparticles for detection of gentamicin in real samples. Anal Methods 9(19): 2853-2858.

35. Smolinska Kempisty K, Guerreiro A, Canfarotta F, Cáceres C, Whitcombe MJ, et al. (2016) A comparison of the performance of molecularly imprinted polymer nanoparticles for small molecule targets and antibodies in the ELISA format 24(6): 37638-37645.
36. Munawar H, Smolinska-Kempisty K, Cruz AG, Canfarotta F, Piletska E, et al. (2018) Molecularly imprinted polymer nanoparticle-based assay (MINA): application for fumonisin B1 determination. Analyst 143(14): 3481-3488.

37. Smolinska-Kempisty K, Guerreiro A, Czulak J, Piletsky S (2019) Negative selection of MIPs to create high specificity ligands for glycated haemoglobin. Sensors and Actuators B: Chemical.

38. Garcia Y, Smolinska-Kempisty K, Pereira E, Piletska E, Piletsky S (2017) Development of competitive 'pseudo'-ELISA assay for measurement of cocaine and its metabolites using molecularly imprinted polymer nanoparticles. Anal Methods 9(31): 4592-4598. 